Schulich School of Law, Dalhousie University

Schulich Law Scholars

Research Papers, Working Papers, Conference

Papers

Faculty Scholarship

$5-28-2016$

\title{
Memorandum Re: Health Canada's 'Draft Guidance' on Section 21.1(3)(C) of the Food and Drugs Act
}

Trudo Lemmens

University of Toronto - Faculty of Law, trudo.lemmens@utoronto.ca

Matthew Herder

Dalhousie University, matthew.herder@dal.ca

Follow this and additional works at: https://digitalcommons.schulichlaw.dal.ca/working_papers

Part of the Health Law and Policy Commons

\section{Recommended Citation}

Matthew Herder, "Memorandum Re: Health Canada's 'Draft Guidance' on Section 21.1(3) (C) of the Food and Drugs Act" (2016) Dalhousie University Schulich School of Law Working Paper No 25.

This Working Paper is brought to you for free and open access by the Faculty Scholarship at Schulich Law Scholars. It has been accepted for inclusion in Research Papers, Working Papers, Conference Papers by an authorized administrator of Schulich Law Scholars. For more information, please contact hannah.steeves@dal.ca. 


\title{
Memorandum re: Health Canada's "Draft Guidance" on Section 21.1(3)(c) of the Food and Drugs Act
}

\author{
May 24, 2016 \\ Matthew Herder ${ }^{a}$ \& Trudo Lemmens ${ }^{\text {b }}$ \\ a JSM LLM, Associate Professor, Health Law Institute, Faculties of Medicine and Law, \\ Dalhousie University; Twitter: @cmrherder \\ ${ }^{\mathrm{b}}$ LicJur, LLM, DCL Professor and Scholl Chair in Health Law and Policy, Faculty of Law \\ and Dalla Lana School of Public Health, University of Toronto; Twitter: @TrudoLemmens

\section{Introduction} \\ [1] In 2014 Parliament enacted a number of amendments to the Food and Drugs \\ Act, R.S.C. 1985, c. F-27 [hereinafter the "F\&D Act"]. Known as "Vanessa's Law," these \\ amendments were intended to enhance the regulation of pharmaceutical drugs and \\ thereby protect Canadians from harm by giving the regulator, Health Canada, new \\ powers to, inter alia, recall drugs, require active post-market surveillance, and improve \\ the transparency of information around pharmaceutical drugs. Vanessa's Law explicitly \\ recognized that "new measures are required to further protect Canadians from the risks \\ related to drugs and medical devices." (emphasis added) (Bill C-17, An Act to Amend \\ the Food and Drugs Act, 2d Sess., 41st Parl., 2014, c. 24, Preamble.)
}

[2] Section 21.1(3)(c) of the F\&D Act provides the power to introduce one of these new measures. It gives the Minister of Health the discretion to share "confidential business information" [hereinafter "CBI"]. The provision reads:

21.1 (3) The Minister may disclose confidential business information about a therapeutic product without notifying the person to whose business or affairs the information relates or obtaining their consent, if the purpose of the disclosure is related to the protection or promotion of human health or the safety of the public and the disclosure is to...

(c) a person who carries out functions relating to the protection or promotion of human health or the safety of the public.

[3] On March 10, 2016, Health Canada published the "Draft Guidance - Document: Disclosure of Confidential Business Information Under Paragraph 21.1(3)(c) of the Food and Drugs Act" [hereinafter "Draft Guidance"]. We submit that this Draft Guidance runs 
counter to both the express wording and spirit of Vanessa's Law. Specifically, Health Canada's position that s. $21.1(3)(c)$ requires those who request information pursuant to this provision to,

i. Demonstrate qualifications as a health professional and research expertise;

ii. Enter into a confidentiality agreement;

iii. Agree not to disclose the information to any third parties; and,

iv. Demonstrate prior efforts to obtain the information from alternative sources;

is contrary to the express wording of section $21.1(3)(c)$, constitutes an ultra vires exercise of statutory authority, substantially undermines the purpose of the provision, viz. to better protect Canadians from harm, and is fundamentally at odds with the scheme and object of the F\&D Act as well as the intention of Parliament in enacting Vanessa's Law. Further, these limitations potentially violate the Charter of Rights and Freedoms. We therefore call upon Health Canada to immediately alter its approach as stated in the Draft Guidance.

[4] In this brief we show that Health Canada's Draft Guidance improperly "reads in" four requirements into section 21.1(3)(c), which run counter to the express wording and spirit of Vanessa's Law. We begin by explaining why Health Canada's practice of treating safety and effectiveness data as $\mathrm{CBI}$ is mistaken and misguided, fails to recognize an internationally recognized need for a new approach to drug safety, and fails to live up to Vanessa's Law's recognition of the need for new transparency measures. Then, we describe the legislative background and purpose of Vanessa's Law, and detail the fundamental flaws in Health Canada's Draft Guidance.

\section{Drug Safety and Effectiveness Data Should Not Regarded as CBI}

[5] No Canadian court has ever squarely considered the issue of whether information pertaining to the safety or effectiveness of a drug falls within the scope of $\mathrm{CBI}$ or should be awarded special protection. (See Herder, Matthew, "Unlocking Health Canada's cache of trade secrets: mandatory disclosure of clinical trial results" (2012) 184:2 Canadian Medical Association Journal 194.) In cases where Health Canada's decision to disclose information pertaining to a drug has been challenged, safety and effectiveness information, such as the findings from an unpublished drug study, has not 
been at issue. (See for e.g. Merck Frosst Canada Ltd. v. Canada (Health), [2012] 1. S.C.R. 23 at para. 215.)

[6] Instead, Health Canada has for decades decided to treat such information as $\mathrm{CBI}$ as a matter of institutional practice. (See Herder, Matthew, "Denaturalizing transparency in drug regulation" (2015) 8:2 McGill Journal of Law \& Health S57.) Vanessa's Law gave credence to the regulator's practice by codifying a broad definition of $\mathrm{CBI}$, which reads as follows:

"confidential business information", in respect of a person to whose business or affairs the information relates, means - subject to the regulations - business information

(a) that is not publicly available,

(b) in respect of which the person has taken measures that are reasonable in the circumstances to ensure that it remains not publicly available, and

(c) that has actual or potential economic value to the person or their competitors because it is not publicly available and its disclosure would result in a material financial loss to the person or a material financial gain to its competitors; [emphasis added]

[7] Despite the broad wording in Vanessa's Law, we submit that any information about a drug's safety or effectiveness should not fall within the codified definition of CBI. It is clinical information, derived from patients in the course of clinical studies or treatment, intended to contribute to the creation of public knowledge that is crucial for the protection of individual patients and the public at large. On its face, such information is not business information.

[8] In addition, the definition of CBI in Vanessa's Law stipulates that the information must hold "actual or potential economic value", such that its disclosure "would result in a material financial loss to the person or a material financial gain to its competitors." (F\&D Act, s. 20) Yet, allowing greater scrutiny of the unpublished information about a drug could only result in financial loss to the person who submitted it if the data does not actually support the claim that the drug is safe and effective. Clearly, Parliament did not intend to enact a regulatory regime that would allow drug companies to make unsubstantiated claims about safety and efficacy when it passed Vanessa's Law. Thus, drug safety and effectiveness data should not be regarded as fulfilling subsection (c) of the statutory definition of $\mathrm{CBI}$. 
[9] Beyond the statutory definition of $\mathrm{CBI}$, the public interest nature of clinical trials data is obvious from its historical origin. The conduct of clinical trials has become an essential component of drug development process, and clinical trials are now a significant cost factor for pharmaceutical companies directly as a result of their introduction as a key requirement for the purpose of establishing drug safety and efficacy. The purpose of these requirements has from their conception been to create information in the interest of patients and the public at large (Lemmens, Trudo, "Pharmaceutical Knowledge Governance: A Human Rights Perspective" (2013) 41(1) Journal of Law, Medicine and Ethics 163). It would be odd to establish a proprietary right to secrecy over data, which from their historical origin are aimed at informing drug regulators, patients and health care providers. On the contrary, these data should be recognized as public goods (Reichman, Jerome H., "Rethinking the role of clinical trial data in international intellectual property law: the case for a public goods approach" (2009) 9 Marq. Intell. Prop. L. Rev. 1; Rodwin, Mark A. \& John D. Abramson, "Clinical trials data as a public good" (2012) 308:9 JAMA 871).

[10] The need for clinical trials data transparency and sharing of data has widely been recognized at the international level in initiatives in which Canada, and Health Canada in particular, has participated. For example, Canada participated in the World Health Organization's [WHO] Global Forum and Ministerial Summit on Health Research in Mexico, which issued a "Statement on Health Research", recognizing the need to promote access to evidence (The Ministerial Summit on Health Research, Mexico City, Mex., Nov. 16-20, 2004, The Mexico Statement on Health Research, Knowledge for Better Health: Strengthening Health Systems, 3 (Nov. 16-20, 2004), available at http://www.who.int/rpc/summit/agenda/en/ mexico_statement_on_health_research.pdf; and World Health Assembly, WHA58.34: Ministerial Summit on Health Research, WORLD HEALTH ORG., http://apps.who.int/gb/ ebwha/pdf_files/WHA58/WHA58_34en.pdf). The commitment to data transparency was reiterated at the 2008 Bamako Global Ministerial Forum on Health. It is also reflected in the Pan American Health Organization Policy on Research for Health (CD49/10), which has been approved for implementation in PAHO by the Member States and the Pan American Sanitary Bureau by the 2009 49th Directing Council of PAHO/WHO. The World Medical Association 
Declaration of Helsinki, which is cross-referenced in Health Canada's Good Clinical Practice Guidance, also specifically recognizes the importance of access to research results. Even though these international instruments focus on trial registration and results reporting, and do not impose a clear duty of full data transparency, the very broad definition of Commercial Confidential Information runs counter to these international commitments to transparency, certainly to the spirit and goal of these commitments.

[11] In other jurisdictions, with similar international commitments to transparency and with similar international obligations under the Trade Related Aspects of Intellectual Property Rights (TRIPS) agreement, drug regulatory authorities have taken a very different approach than Health Canada. Europe in particular has moved away from the approach Canada adheres to, of treating access to data as an exception that has to be justified, rather than as a rule that may have some exceptions. In January 2015, the new European Medicines Agency's (EMA) Policy on Publication of Clinical Data for Medicinal Products for Human Use came into force. This Policy, introduced in accordance with article 80 of Regulation (EC) No 726/2004, has a similar purpose as the transparency provisions of Vanessa's Law. The Policy confirms the Agency's respect for what it terms "commercial confidential information" (CCl), but it states explicitly: "In general...clinical data cannot be considered $\mathrm{CCl}$. The Agency acknowledges that there are limited circumstances where information could constitute CCl." (emphasis added) Further, the EMA puts the onus on those who invoke the commercial confidential information to provide evidence that the information in question falls in that category.

[12] Consistent with its longstanding practice, but contrary to international developments, Health Canada continues to treat drug safety and effectiveness information, including unpublished clinical studies of a drug, as CBI. The regulator is likely to continue to do so unless and until regulations that further clarify the scope of $\mathrm{CBI}$ are drafted pursuant to Vanessa's Law. (F\&D Act, s. 30(1.2)(d.1).)

[13] We strongly object to this interpretation of the scope of CBI. We urge Health Canada to immediately exclude drug safety and effectiveness information from the scope of $\mathrm{CBI}$ as a matter of practice as well as draft regulations to that same effect in an 
expedited manner. The fundamental flaws in Health Canada's Draft Guidance that we outline below exacerbate this problematic approach regarding the scope of $\mathrm{CBI}$.

\section{Legislative History, Scheme \& Purpose of Vanessa's Law}

[14] Pharmaceutical products such as drugs are aimed at treating disease and improving people's health. In order to do so, the benefits of drugs have to outweigh their risks. Drugs will rarely, if ever, have no side effects. Regulators like Health Canada carefully look at the risk/benefit profile of drugs in order to determine when the potential benefits of a drug outweigh its risks, and what information ought to be provided to health care providers and patients about the drug. Based on this assessment, it decides which drugs can be sold, prescribed, and consumed, and what information has to be provided. It is a challenging task. Regulators may miss safety problems in the evidence base behind a given drug, or drug manufacturers may bury information that does not favour their product. In other instances, safety problems may only be detected after years of use of the drug by patients. Further, when safety concerns with a drug arise but the precise cause is uncertain, delays in removing the drug from the market may precipitate additional harm to patients. There is strong historical evidence that hiding of safety and efficacy data and misrepresentation of findings occurs as a result of the significant financial interest in selling pharmaceutical products.

[15] Vanessa's Law was designed to address some of these challenges. When it was introduced for first reading in Parliament on December 6, 2013, Bill C-17 included a number of provisions that stood to improve patient safety. For example, Bill C-17 included a new power to recall drugs for reasons of safety. It also empowered the regulator to compel drug manufacturers to conduct active, post-market surveillance. However, Bill C-17 was originally devoid of any provisions designed to improve the transparency of information about pharmaceutical safety and/or effectiveness. (See Herder, Matthew et al., "Regulating prescription drugs for patient safety: Does Bill C-17 go far enough?" (2014) 186:8 CMAJ E287.)

[16] Greater transparency is essential to ensuring Canadians are not harmed from unsafe, ineffective drugs. The drug rofecoxib (tradename: Vioxx) offers a powerful 
example. Vioxx was approved in 1998 for the treatment of arthritic pain only to be withdrawn from markets worldwide in 2004 due to its association with increased cardiac arrest and death. Regulatory officials knew of this safety risk, however, they kept it private on the grounds that that information was the property of the drug manufacturer. It is estimated that hundreds of thousands of patients suffered a cardiac arrest and died after taking this regulatory approved, physician-prescribed drug. (See "Vioxx: lessons for Health Canada and the FDA" (2005) 172:1 CMAJ 5; Graham, David J et al., "Risk of acute myocardial infarction and sudden cardiac death in patients treated with cyclooxygenase 2 selective and non-selective non-steroidal anti-inflammatory drugs: nested case-control study" (2005) 365:9458 Lancet 475.)

[17] Following Vioxx's withdrawal and a spate of similar tragedies, international organizations such as the World Health Organization have taken initiatives to promote transparency, while the Ministers of Health (including Canada's Minister) also confirmed in the context of WHO Ministerial Summits their countries' commitment to do so. As mentioned earlier, other jurisdictions, in particular Europe, have put into place detailed transparency measures in relation to pharmaceutical products. In sharp contrast, Canada lacked any such legal requirements and Bill C-17 did not promise to remedy the situation when it was first introduced in Parliament.

[18] This fundamental shortcoming in the proposed legislation was highlighted in the medical literature, the media, and the House of Commons. The federal government responded by amending Bill C-17. Several provisions intended to improve transparency were added during the legislative process. They include a mandatory requirement for drug manufacturers to make "prescribed information" about studies testing a drug's safety and/or effectiveness publicly available (s. 21.71); a power to make regulations requiring the Minister of Health to make "publicly available" decisions "with regard to the issuance, amendment, suspension and revocation of authorizations" to market a drug (s. 30(1.1)(b.1)); and, discretionary powers to disclose "confidential business information" in the event that the "Minister believes that the product may present a serious risk of injury to human health" (s. 21.1(2)), or if the "purpose of the disclosure is related to the protection or promotion of human health or the safety of the public and the disclosure is 
to... a person who carries out functions relating to the protection or promotion of human health or the safety of the public." (s. 21.1(3)(c))

[19] Together, these various provisions have the potential to significantly improve the transparency of the evidence base behind pharmaceutical interventions generated in the course of research (s. 21.71), the decisions which Health Canada makes in light of that evidence (s. 30(1.1)(b.1)), and the information upon which those decisions are based, whether to avoid a "serious risk of injury to human health" (s. 21.1(2)) or to proactively engage persons outside the regulator in "the protection or promotion of human health or the safety of the public" (s. 21.1(3)(c)). They promise to establish a much more transparent evidence base around pharmaceuticals and improve public accountability of the drug regulatory system. Some provisions will require implementing regulations to take effect. For instance, regulations are needed to clarify what information manufacturers will be required to make publicly available under s. 21.71. In the meantime, the Minister's new discretionary powers to make information available to avoid injury and proactively screen for potential safety concerns pursuant to sections 21.1(2) and 21.1(3)(c), respectively, are crucially important.

[20] Former Member of Parliament, Terence Young, whose daughter, Vanessa, died from an adverse reaction to a drug, and for whom Bill C-17 was eponymously named, emphasized the importance of these transparency related amendments before the House of Commons' Standing Committee on Health on September 24, 2014. He said, in part,

When I saw the amendments that I was able to present in committee that added a whole clinical trial transparency piece to this bill, I have to tell you, I was thrilled. I didn't know they had them ready, but I know one individual in Health Canada has been working on this bill for 14 years. I'm convinced they will do it right and they'll get the regulations right. But the devil is in the details, and so you look at the intent and the competency of the people.

[21] The transparency related amendments to Bill C-17 were approved by Parliament and given royal assent on November 6, 2014. As testament to the importance of transparency to the enacted legislation's purpose, a third paragraph was integrated into the summary of the legislation: 
This enactment amends the Food and Drugs Act regarding therapeutic products in order to improve safety by introducing measures to, among other things,

(a) strengthen safety oversight of therapeutic products throughout their life cycle;

(b) improve reporting by certain health care institutions of serious adverse drug reactions and medical device incidents that involve therapeutic products; and

(c) promote greater confidence in the oversight of therapeutic products by increasing transparency. [emphasis added]

[22] Improving the transparency of the evidence behind pharmaceutical interventions as well as the regulator's decision-making is thus central to the purpose of Vanessa's Law. Health Canada has echoed the importance of transparency in numerous news releases and policy documents since the passage of Vanessa's Law. However, the regulator's Draft Guidance has the potential to significantly undermine this objective of improving "oversight of therapeutic products by increasing transparency."

\section{Health Canada's Draft Guidance on Section 21.1(3)(c)}

[23] Health Canada's Draft Guidance sets out the parameters regarding how the regulator proposes to utilize the new discretionary power in s. 21.1(3)(c) of the F\&D Act. We focus on four aspects in particular, which stem from sections 3.1(i)-(iii), 3.2, 6 and 8 of the Draft Guidance. For convenience, we reproduce these sections below:

\subsection{PRINCIPLES}

i. Consistent with the objectives of the Protecting Canadians from Unsafe Drugs Act, information disclosed under this authority should contribute to improving the health of Canadians. Requests for disclosure under this authority should clearly define how the purpose relates to this objective and include a formal plan to use the information to advance knowledge, including making results publicly available.

ii. Use of this authority should be necessary to achieve the purpose for which the information is requested. A decision on whether or not to disclose $\mathrm{CBI}$ will include consideration of whether or not all other possible sources of the information, including from the originator of the information, have been exhausted. Only information that is directly related to the purpose set out in the request should be considered for disclosure.

iii. Information disclosed under this authority should be kept confidential and used only for non-commercial purposes. Prior to disclosure, Health Canada requires that potential recipients of CBI sign a legally 
binding agreement to maintain confidentiality, except as permitted

by specific exclusions. Requesters are also required to confirm that the information will not be used for commercial purposes, and to report any activities that could result in a conflict of interest. These requirements are not intended to prevent publication of the results of analyses of the disclosed information.

\subsection{CONSIDERATIONS - PERSONS TO WHOM CONFIDENTIAL BUSINESS INFORMATION (CBI) MAY BE DISCLOSED}

Health Canada's decision regarding disclosure of $\mathrm{CBI}$ includes an assessment of whether the person to whom the CBI would be disclosed fulfills the Act's requirement that they be a person who carries out functions relating to the protection or promotion of human health or the safety of the public.

Where disclosure of $\mathrm{CBI}$ has been requested by an individual, Health Canada expects that the principal requester would have qualifications in a health profession and demonstrated expertise in the subject of the request.

Where disclosure of $\mathrm{CBI}$ has been requested by a corporation, Health Canada expects that its corporate mandate, as described in its articles of incorporation or other documentation, would include purposes relevant to the protection or promotion of human health or the safety of the public and the health or safety issue that is the subject of the request. In addition, it is expected that the designated representative of the corporation identified in the request would have qualifications in a health profession and demonstrated expertise in the topic of the research.

An assessment of the qualifications of a requester may include other considerations, including:

- Relevance of the requester's qualifications to the purpose of the proposed disclosure. Requesters should have the necessary expertise to lead the proposed project. Projects requiring specialized technical expertise may involve collaborators, who should be identified at the request stage where possible.

- Record of contribution to improving the health and/or safety of Canadians in an area relevant to the subject of the request. Publications and research projects related to health and safety issues other than the subject of the request may be taken into account in assessing a request.

- Record of disseminating information to advance scientific knowledge for non-commercial purposes. Where the requester is a corporation, its legal status (for-profit, not-for-profit) may be considered in assessing the risk of a conflict of interest.

\section{MAINTAINING CONFIDENTIALITY OF DISCLOSED INFORMATION}


Health Canada requires requesters to sign a legally binding Confidentiality Agreement to maintain the confidentiality of disclosed information. Among other things, this Agreement provides that the disclosed information can be used only for the purposes of the proposed project and must be kept confidential using appropriate safeguards. The Confidentiality Agreement also prohibits reproduction of disclosed information. The Agreement provides exclusions to the confidentiality obligations, such as for information that is in the public domain, received from another source or for information that the originator has consented to be released. The requester is free to publish results of the analysis as long as the confidentiality of the disclosed information is maintained.

\section{REQUIREMENTS FOR PERSONS REQUESTING DISCLOSURE OF CONFIDENTIAL BUSINESS INFORAMTION UNDER PARAGRAPH 21.1(3)(C)}

Health Canada expects that decisions regarding disclosure of $\mathrm{CBI}$ under paragraph 21.1(3)(c) will normally be in response to a request from an individual or corporation. For this purpose, Health Canada provides a request form that should be completed by requesters. All requests should include the following information:

- Personal and contact information for the principal requester.

- Professional information for the principal requester, including professional qualifications, employment and relevant research experience.

- Names and positions of project collaborators.

- A description of the information requested, including the therapeutic product and regulatory functions to which the information relates. Requesters are encouraged to consult Health Canada's on-line databases of regulatory information and other resources in order to specify their requests as much as possible.

- Indication that the requester has exhausted other sources of the information requested, including from the originator of the information.

- A project summary that clearly indicates the purpose of the proposed disclosure and how it relates to the protection or promotion of human health or the safety of the public.

- Confirmation that the requested information will not be used for commercial purposes.

If a request is incomplete, a requester may be asked to provide missing information. Where Health Canada's assessment finds that the request meets the requirements of the Act, a requester will be asked to provide additional information required to prepare a recommendation regarding disclosure. This will include:

- A completed Conflict of Interest Declaration that provides information required by Health Canada to assess whether or not the requester's financial interests and other affiliations may conflict with their use of the requested information. 
- A signed Confidentiality Agreement with Health Canada that would take effect only if and when Health Canada decides to disclose CBI to the requester.

- A dissemination plan to make the results of the project publicly available. [emphasis added]

[24] In effect, the Draft Guidance proposes to limit the scope of s. 21.1(3)(c) of the F\&D Act to individuals that are,

i. recognized health professionals who intend to use the requested $\mathrm{CBI}$ in a specific research project, and who are also willing to:

ii. Sign a "legally binding Confidentiality Agreement";

iii. agree not to reproduce, in whole or in part, the disclosed information; and,

iv. demonstrate a priori that they have "exhausted other sources of the information requested, including from the originator of the information."

[25] These four limitations have no basis in law and sound policy-making. Below, we show that limiting the application of s. 21.1(3)(c) to those circumstances is contrary to the express wording of the provision and the purpose of Vanessa's Law, confers to the Minister powers that Parliament did not grant, and undermines the efficacy of a regulatory framework in achieving its public interest oriented goals. The barriers it creates to an effective sharing of data are so significant that it undermines the very purpose of the $F \& D$ Act's transparency provisions.

\section{The Draft Guidance's Imposition of Four Limitations on Disclosure is Ultra Vires as it Has No Statutory Basis, and Runs Counter to Both the Express Wording and Purpose of Vanessa's Law}

[26] As the Supreme Court of Canada has repeatedly stressed, statutory interpretation is guided by Driedger's "modern principle". (See Re Rizzo \& Rizzo Shoes Ltd., [1998] S.C.J. No. 2 at para. 21, [1998] 1 S.C.R. 27 (S.C.C.)) The modern principle provides:

Today there is only one principle or approach, namely, the words of an Act are to be read in their entire context in their grammatical and ordinary sense harmoniously with the scheme of the Act, the object of the Act and the intention of Parliament. (See Elmer A. DRIEDGER, The Construction of Statutes, 2nd ed., Toronto, Butterworths, 1983, at 87)

[27] The provisions of the F\&D Act, considered in their entire context, cannot be interpreted as authorizing the Minister to limit disclosure of information in the manner proposed. A plain reading of section 21.1(3)(c) of the F\&D Act reveals none of the four 
limitations introduced by Health Canada's Draft Guidance. There is no mention of a (i) restricting eligible persons to health professionals with demonstrable research expertise; (ii) the use of confidentiality agreements, (iii) limitations upon subsequent disclosure of the information, or (iv) a need to attempt to secure access to the information in question from other sources before making a request under section 21.1(3)(c). Indeed, the pharmaceutical industry was at pains to highlight the very omission of requirements such as (ii) or (iii) from the legislation when providing testimony before the Standing Senate Committee on Social Affairs, Science and Technology on Bill C-17:

Both the lowered threshold for the release of $\mathrm{CBI}$ and the lack of provisions holding recipients of $\mathrm{CBI}$ to respect that confidentiality are at odds with the practices of our major trading partners. These provisions are also at odds with the principles underlying the Regulatory Cooperation Council, established by the Canadian and U.S. governments. The success of this initiative relies on the free flow of information between the regulatory agencies of each country, which could be undermined if their respective treatment of $\mathrm{CBI}$ does not align. (See Proceedings of the Standing Senate Committee on Social Affairs, Science and Technology, Oct. 1, 2014, Gerry Harrington, Director of Public Affairs, Consumer Health Products Canada) [emphasis added]

Nevertheless, following the enactment of Vanessa's Law, Health Canada has chosen to read in those four limitations into section 21.1(3)(c).

[28] To the extent that the Draft Guidance document imposes new obligations on those requesting access to data that Parliament did not explicitly empower the Minister to impose, the Draft Guidance is also ultra vires. The only discretionary power granted to the Minister under Vanessa's Law is the power to determine whether the purpose of the disclosure is "related to the protection or promotion of human health or the safety of the public" and whether the disclosure is to a qualified person. These are the only explicit conditions for the exercise of the discretionary power mentioned under the F\&D Act. Yet, the Draft Guidance imposes at least two inter-related new obligations to requesters of information: to sign a confidentiality agreement and thus to keep the data confidential, and not to reproduce the information, in whole or in part, to third parties.

[29] These two new obligations go beyond what Parliament authorized when enacting Vanessa's Law. Indeed, the legislation explicitly allows the Minister to disclose data for 
public health and safety purposes. When exercising that discretionary power, the data ceases to constitute $\mathrm{CBI}$, assuming it was properly categorized as such in the first place. Thus, the imposition of a confidentiality obligation and the imposition of an obligation not to further share data not only have no statutory basis, they are also in contradiction with the power granted to the Minister. Nothing in the statute empowers the Minister to create an exclusive right over the use of that information. The statute's granting of power to enact further regulations or guidance documents in relation to the disclosure is not a sufficient basis to create specific conditions that are not mentioned under the F\&D Act.

[30] Recent jurisprudence supports this conclusion. The Supreme Court of Canada has recognized that jurisdiction-granting provisions are not analogous to general regulation or policy making because the former are express grants of specific authority from Parliament while the latter must be interpreted so as not to confer unfettered discretion not contemplated by the jurisdiction-granting provisions of the legislation (Reference re Broadcasting Regulatory Policy CRTC 2010-167 and Broadcasting Order CRTC 2010-168, [2012] 3 S.C.R. 489 at para. 27). Thus, the power to enact further regulations or guidance documents cannot serve to broaden the discretion Parliament saw fit to confer upon the Minister in s. 21.1(3)(c).

[31] More generally, the power to enact regulations and implement a regulatory scheme does not give rise to any power to create new duties or new rights that are not explicitly mentioned in the $F \& D$ Act, such as in this case obligations to keep information confidential and a right of exclusive use with respect to disclosed information (see Broadcasting Order CRTC 2010-168, [2012] 3 S.C.R. 489, 2012 SCC 68, paras. 11-13 and para. 81; and ATCO Gas \& Pipelines Ltd. v. Alberta (Energy \& Utilities Board), [2006] 1 S.C.R. 140: paras. 5, 7, 49-51, 74, 77-78).

[32] In our view, these new obligations are also neither essential nor sufficiently related to the purpose of Vanessa's Act to support a claim that these conditions have to be read into the legislation. The doctrine of jurisdiction by necessary implication, even if applicable,_can only justify measures that are directly related to the purpose of the regulatory framework, i.e. the protection of the health and safety of Canadians. The obligations imposed are in fact contrary to the purpose of the regulatory framework, as 
they aim at protecting and safeguarding alleged commercial interest in the data, which the Minister is explicitly authorized to disregard for the purpose of the protection of public health and safety.

[33] As we indicated at the outset, reading in these four limitations is also more generally irreconcilable with the "scheme of the Act, the object of the Act and the intention of Parliament" and therefore not a reasonable exercise of Health Canada's regulatory role. Below, we expand on why they are fundamentally at odds with the scheme and object of the F\&D Act as well as the intention of Parliament.

i. Limiting Persons Eligible to Make a Request to Health Professionals with Research Expertise Runs Counter to the Purpose of Vanessa's Law

[34] CBI can be shared under s. 21.1(3)(c) with persons who carry "out functions relating to the protection or promotion of human health or the safety of the public." During the legislative process, expert witnesses urged Parliamentary committees to list the types of persons that fell within that category. (See Proceedings of the Standing Senate Committee on Social Affairs, Science and Technology, Sept. 25, 2014, Matthew Herder, Dalhousie University) However, Parliament chose not to do so within the four corners of the legislation, suggesting that Parliament did not intend to limit the types of persons who are eligible to receive CBI pursuant to s. 21.1(3)(c). Rather, Parliament intended that such persons be interpreted in an open-ended, flexible fashion, recognizing that many different types of persons carry out different types of functions, each of which may positively contribute to the protection and promotion of human health or public safety.

[35] The effect of the Draft Guidance is to unlawfully fetter the Minister's broad discretion to disclose information to persons who carry out functions relating to the protection or promotion of human health or the safety of the public. It is trite law that a non-statutory instrument cannot pre-empt the exercise of a regulator's discretion in a particular case, such as where the requester fails to meet one of the four conditions set out in the Draft Guidance. 
[36] Further, Parliament's choice of an open-ended approach - not Health Canada's Draft Guidance-comports with how important drug safety and effectiveness concerns have been identified in the past. The importance of transparency is highlighted by the fact that it have often been external scientists - not drug regulators - who have alerted the public about serious problems with pharmaceutical products that were on the market, for example with Hormone Replacement Therapy (Rossouw JE et al., "Risks and benefits of estrogen plus progestin in healthy postmenopausal women: principal results from the Women's Health Initiative randomized controlled trial" (2002) 288:3 JAMA 321); Avandia (Nissen S.E. and Wolski K., "Effect of rosiglitazone on the risk of myocardial infarction and death from cardiovascular causes" (2007) 356:24 N Engl J Med. 2457); SSRIs (Healy D., Pharmageddon. Berkeley: University of California Press; 2012.); and, Januvia-Byetta (Cohen D, "Has pancreatic damage from glucagon suppressing diabetes drugs been underplayed?" (2013) 346 BMJ f3680). Public interest oriented scientists provide critical analysis of data and contribute thereby to the protection of patients and the public at large. A careful and sometimes repeated analysis of data and understanding of research results is a crucial first step, and timely access to data is therefore essential. In short, it saves lives. Health Canada's interpretation of s. 21.1(3)(c) would prevent such organizations from playing such a vital, life-saving role.

[37] Parliament's choice of an open-ended approach-not Health Canada's Draft Guidance-also stands to help practising health professionals who may not have active research agendas, but nevertheless play an integral role in protecting and promoting human health. For example, many doctors do not have active research agendas. Still, in order to make informed decisions about whether to prescribe a drug they should ideally be informed of all of the risks and benefits of that drug. Access to the information that Health Canada has in respect of that drug - not just the information in the published literature, which is frequently skewed in favour of the drug (Song, F et al., "Dissemination and publication of research findings: an updated review of related biases" (2010) 14:8 Health Technol Assess iii)-can therefore assist doctors in making more informed prescribing decisions. Yet, Health Canada's move to require doctors to design a research study in order to take advantage of s. 21.1(3)(c) would deny doctors' ability to carry out a basic function, which clearly protects and promotes human health. 
[38] The Draft Guidance's proposed limitation upon who fits within the category of persons that perform functions that protect or promote human health or public safety is thus impossible to square with the express wording and purpose of the provision.

\section{ii. Requiring a Confidentiality Agreement Runs Counter to the Purpose of Vanessa's Law}

[39] Health Canada's decision to require those who seek CBI pursuant to s. 21.1(3)(c) to sign a confidentiality agreement appears to follow from the nature of the information involved. That is, Health Canada has reasoned that because CBI is involved, it should only be shared with eligible persons under conditions of confidentiality.

[40] However, this reasoning does not follow when considered in light of Canada's international obligations, relevant caselaw regarding the scope of Minister's authority when exercising a statutory power, much less the scheme and object of the F\&D Act or the intention of Parliament.

[41] First, despite the regulator's longstanding practice of doing so and industry's inaccurate contention that the regulator must do so, Health Canada is under no absolute international obligation to maintain the confidentiality of information that it receives from drug manufacturers. Rather, existing international treaties require that Health Canada protect data that it receives in confidence against "unfair commercial use." (North American Free Trade Agreement Between the Government of Canada, the Government of Mexico and the Government of the United States, 17 December 1992, Can. T.S. 1994 No. 2, 32 I.L.M. 289 (entered into force 1 January 1994); WTO Agreement on Trade-Related Aspects of Intellectual Property Rights, 15 April 1994, 33 I.L.M. 1197). Countries may meet this obligation through diverse measures (see Ho, Cynthia. Access to Medicine in the Global Economy: International Agreements on Patents and Related Rights (OUP USA, 2011), such as granting a limited period of data exclusivity to drug companies (see Lemmens, Trudo \& Candice Telfer, "Access to Information and the Right to Health: The Human Rights Case for Clinical Trials Transparency" (2012) 31(1) Am. J. Law \& Med. 63 at pp. 83-87), which Canada has done. (Food and Drug Regulations, C.R.C., c. 870, C.08.004.1) As pointed out earlier, Europe has taken a very 
different approach to its obligations under TRIPS. Thus, international law does not support the conclusion that $\mathrm{CBI}$ can only be shared under conditions of confidentiality.

[42] Second, courts have placed important boundaries upon a Minister's exercise of a statutory power. Most notably, a non-statutory instrument cannot impose mandatory requirements enforceable by sanction, such as, in our view, a mandatory confidentiality agreement backed by an indemnity in favour of the Crown. Put simply: the Minister cannot issue de facto laws disguised as guidelines (see for e.g. Ainsley Financial Corp. v. Ontario (Securities Commission), 1994 CanLII 2621 (ON CA)).

[43] Third, close attention to the scheme and object of the F\&D Act, as well as the intention of Parliament in enacting Vanessa's Law, also suggests that the regulator's purported use of confidentiality agreements in exercising s. 21.1(3)(c) is problematic. To make this point, it is helpful to contrast s. $21.1(3)(c)$ with the scheme of the Access to Information Act, R.S.C. 1985, c. A-1 (the "ATI Act").

[44] Under the ATI Act Canadian citizens and residents have a general right of access to "any record under the control of a government institution." It is a right, not a privilege. Provided the record in question is within the control-broadly interpreted-of any federal government body, Canadians must be given access to it (Canada Post Corp. v. Canada (Minister of Public Works), [1995] 2 F.C. 110 (F.C.A.)), subject only to certain exceptions.

[45] Some of these ATI Act exceptions mirror the definition of CBI now enshrined in the F\&D Act following the passage of Vanessa's Law. Section 20(1) of the ATI Act provides in part:

20(1) Subject to this section, the head of a government institution shall refuse to disclose any record requested under this Act that contains

(b) financial, commercial, scientific or technical information that is confidential information supplied to a government institution by a third party and is treated consistently in a confidential manner by the third party; 
(c) information the disclosure of which could reasonably be expected to result in material financial loss or gain to, or could reasonably be expected to prejudice the competitive position of, a third party;

[46] However, the scheme of the F\&D Act is fundamentally different from the scheme of the ATI Act. Under the ATI Act the exemptions contained in s. 20(1) of the legislation are mandatory. If the information in question fits within s. 20(1)(b) or sub-(c) the head of the government institution must refuse disclosure unless the "public interest override" contemplated in s. 20(6) of the ATI Act is invoked-a measure which is seldom if ever invoked. Further, the ATI Act also confers a measure of "procedural protection" to third parties where the head of a government institution has reason to believe information within the meaning of s. 20(1) may be involved. In such instances, heads of government institutions must give notice to the third parties involved and afford them an opportunity to respond to any potential disclosure. (see Merck Frosst Canada Ltd. v. Canada (Health), [2012] 1 S.C.R. 23, at paras. 23, 27-28.)

[47] In marked contrast, s. 21.1(3)(c) of the F\&D Act is a discretionary power created for the purpose of sharing $\mathrm{CBI}$ under certain circumstances; namely, where the $\mathrm{CBI}$ is sought by a person who protects or promotes human health or public safety and he or she is seeking the information in question for the purpose of protecting or promoting human health or public safety. The provision, moreover, explicitly states that no notice or consent from "the person to whose business or affairs the information relates" is required before $\mathrm{CBI}$ is shared.

[48] The scheme of the F\&D Act thus reflects Parliament's intention to treat $\mathrm{CBI}$ pertaining to drugs differently from purportedly similar third party information under the ATI Act because different considerations are in play, viz. the health and safety of Canadians. In amending Bill C-17 during the legislative process, Parliament recognized that improving the level of transparency around pharmaceutical interventions was essential to improving the "oversight of therapeutic products." The amendments made to the F\&D Act in Vanessa's Law thus mark a departure from the way in which drug related $\mathrm{CBI}$ was dealt with under the ATI Act. 
[49] Health Canada's Draft Guidance, which purports to impose a legal obligation of confidentiality upon those who request CBI pursuant to s. 21.1(3)(c), is fundamentally at odds with the scheme and object of the F\&D Act and Parliament's intention. In enacting s. s. 21.1(3)(c) as well as other amendments designed to improve transparency (see ss. 21.1(2), 21.4(2), 21.71), Parliament chose to break from past practice of keeping information confidential given the public health risks of continued secrecy. Health Canada's Draft Guidance attempt to continue its practice of confidentiality is thus inconsistent with the will of Parliament.

\section{iii. Precluding Disclosure of Information to Third Parties for the Purpose of Protecting or Promoting Human Health or Public Safety Runs Counter to the Purpose of Vanessa's Law}

[50] Maintaining the confidentiality of $\mathrm{CBI}$ is at odds with Parliament's intention not only because it purports to continue the regulator's past practice of secrecy, but also because it will undermine the express goal of s. 21.1(3)(c). Parliament recognized that persons who protect human health or public safety will be assisted in doing so when given access to pharmaceutical CBI. However, Health Canada's Draft Guidance threatens that very task in additional ways.

[51] In particular, Health Canada's Draft Guidance precludes persons that are otherwise eligible to receive $\mathrm{CBI}$ from reproducing, in whole or in part, that same $\mathrm{CBI}$. The Draft Guidance does allow such persons to disseminate "results", for example, where the $\mathrm{CBI}$ is analyzed for research purposes. But they are prohibited from sharing the information from which those results are derived.

[52] This may appear to strike a reasonable balance, however, the dissemination of research findings through reputable journals is increasingly contingent upon sharing the underlying data behind those findings. (Teichman, Darren B. et al., "Sharing clinical trial data: A proposal from the International Committee of Medical Journal Editors" (editorial) (2016) 164(7) Ann. Intern. Med. 505 doi:10.7326/M15-2928) Leading researchers and organizations in the sphere of biomedical research recognize that in order for research to be truly open to scrutiny fulsome data sharing is necessary. (See for e.g. Institute of Medicine. Sharing Clinical Trial Data: Maximizing Benefits, Minimizing Risk, online: 
<http://books.nap.edu/openbook.php?record_id=18998>.) Precluding those who access $\mathrm{CBI}$ pursuant to s. 21.1(3)(c) from sharing that information will thus limit their ability to disseminate their findings through reputable journals-one of the most important avenues of communication within the biomedical community, amongst all health professionals, to patients, and the public at large.

[53] More fundamentally, it is impossible to detect selective reporting and outright fabrication of results without data openness, to the detriment of public health. For example, a recent re-analysis of the research data used to justify the use of the antidepressant paroxetine (tradename: Paxil) in adolescents reveals that the drug was neither safe nor effective for that population. (see Noury, Joanna Le et al., "Restoring Study 329: efficacy and harms of paroxetine and imipramine in treatment of major depression in adolescence" (2015) 351 BMJ h4320.) The paroxetine case is far from an isolated example in the pharmaceutical context where the financial incentive to skew research findings in favour of a drug are powerful. Therefore, in order to ensure that decisions about whether to approve a drug for sale or prescribe its use are truly evidence-based, access to the data underlying research-not just the results of research - is of fundamental importance.

[54] By reading in a limitation of disclosing only the results of any research or analysis carried out with information shared under s. 21.1(3)(c), Health Canada's Draft Guidance is in fact more apt to undermine, rather than serve, the goal of protecting and promoting human health or public safety.

iv. Demonstrating Other Sources of Information have been Exhausted Runs Counter to the Purpose of Vanessa's Law

[55] Section 8 of the Draft Guidance stipulates in part that requests made under s. 21.1(3)(c) should provide an "indication that the requester has exhausted other sources of the information requested, including from the originator of the information." In addition, listed amongst the Guiding Principles in s. 3.1 of the Draft Guidance is the following:

Use of this authority should be necessary to achieve the purpose for which the information is requested. A decision on whether or not to disclose CBI will include consideration of whether or not all other possible sources of the 


\section{information, including from the originator of the information, have been}

exhausted. Only information that is directly related to the purpose set out in the request should be considered for disclosure. [emphasis added]

[56] Some companies have indeed begun to make some drug information available through their own or third-party data platforms. (Krumholz, Harlan M et al., "A Historic Moment for Open Science: The Yale University Open Data Access Project and Medtronic" (2013) 158:12 Ann Intern Med 910; Doshi, P., "Putting GlaxoSmithKline to the test over paroxetine" (2013) 347:nov12 2 BMJ f6754; Doshi, P., "From promises to policies: is big pharma delivering on transparency?" (2014) 348:feb26 2 BMJ g1615) However, requiring putative requesters to attempt to secure information from such sources betrays a fundamental misunderstanding of why access to $\mathrm{CBI}$ stands to help protect and promote human health.

[57] In short, there is no guarantee that any source of information is the same. In some documented cases, pharmaceutical companies have misled regulators, providing only some of the information pertaining to a given drug. Therefore, to ensure that regulators are able to make informed decisions, it is essential to have access to the information they hold regardless of whether access can be secured from other sources.

[58] Further, the originators of the of information (i.e. pharmaceutical companies) have an incentive to appear as though they are transparent in the public eye while in practice working to delay and complicate researchers' access to, and analysis of, the information, particularly where the purpose of the research is interrogate past findings that support a drug on the market. This is precisely what occurred in the paroxetine case. The originator, GlaxoSmithKline, ultimately provided access to the data in question. But they did so slowly and in a manner that was far from conducive to analysis; the researchers involved had to scrutinize thousands of pages of data in 'read only' format on a company computer. (Doshi, P., "Putting GlaxoSmithKline to the test over paroxetine" (2013) 347:nov12 2 BMJ f6754; Noury et al., supra.) The obligation to try to obtain data from all other possible sources will thus delay access to data and create an often insurmountable practical burden for health researchers and others.

[59] Introducing this procedural hurdle into s. 21.1(3)(c) of the F\&D Act is also eerily similar to what prevented "Canada's Access to Medicine Regime" (CAMR) from 
achieving its core purpose. CAMR was a law that was intended to facilitate access to essential medicines in less developed countries. However, amongst other requirements, CAMR stipulated that would-be manufacturers of such essential medicines to populations in need must first try to negotiate a license with patent-holders before they could take advantage of CAMR. This completely undermined the effectiveness of CAMR: nearly a decade into its existence, CAMR has only resulted in one essential medicine being produced for one country by one manufacturer. (Elliott, Richard., "Fixing Canada's Access to Medicines Regime - Bill C-398", (18 November 2012), online: Intellectual Property Watch <http://www.ip-watch.org/2012/11/18/fixing-canadasaccess-to-medicines-regime-bill-c-398/>.) The requirement that would-be recipients of information under s. s. 21.1(3)(c) first seek that information from all other possible sources being proposed in Health Canada's Draft Guidance stands to have a substantially similar effect.

\section{The Draft Guidance Potentially Violates Sections 2(b) and 7 of the Charter of Rights and Freedoms}

[60] The Supreme Court of Canada has long taken a generous and purposive approach to the interpretation of the rights and freedoms guaranteed by the Charter, including the freedom of expression guaranteed by s. 2(b) (Greater Vancouver Transportation Authority v. Canadian Federation of Students - British Columbia Component, [2009] 2 S.C.R. 295 at para. 27). As explained by the Court,

[i]t is difficult to imagine a guaranteed right more important to a democratic society than freedom of expression. Indeed a democracy cannot exist without that freedom to express new ideas and to put forward opinions about the functioning of public institutions. The concept of free and uninhibited speech permeates all truly democratic societies and institutions. The vital importance of the concept cannot be over-emphasized" (Edmonton Journal v. Alberta (Attorney General), [1989] 2 SCR 1326 at pp. 1336, per Cory J., cited in part with approval in Vancouver Sun (Re), [2004] 2 S.C.R. 332 at para. 23). 
[61] Parliament recognized as much by adding to the summary of the legislation the following statement of purpose: to "promote greater confidence in the oversight of therapeutic products by increasing transparency."

[62] In accordance with this generous and purposive approach, an activity by which one conveys or attempts to convey meaning will prima facie be protected by s. 2(b) (Irwin Toy Ltd. v. Quebec (Attorney General), [1989] 1 S.C.R. 927 at pp. 968-69 and Greater Vancouver Transportation Authority at para. 27). In addition, it has long been recognized that s. 2 (b) protects the right to receive as well as broadcast expression (Vancouver Sun at para. 26, and Baier v. Alberta, [2007] 2 S.C.R. 673 at para. 40).

[63] In our view, requesters are entitled to express themselves by publishing their research and speaking to patients, colleagues and the media regarding the risks and benefits of drugs; they are further entitled to obtain and use information that may be relevant or even essential to protect and promote one's health (and thus, as discussed below, the right to life and security of the person).

[64] In this respect, we emphasize that s. 2(b) protects not only the right of requesters, but also the right of the public, to receive information regarding the safety and effectiveness of drugs. Much like the press plays a vital role in being the conduit through which the public receives information regarding the operation of public institutions (Edmonton Journal at pp. 1339-40), so too eligible persons play a vital role in accessing, analyzing and interpreting safety and effectiveness data for the broader public.

[65] It matters not, in our view, whether the right sought is described as positive or negative. As explained by L'Heureux-Dubé J. in Haig v. Canada, [1993] 2 S.C.R. 995 at p. 1039 ,

The distinctions between "freedoms" and "rights", and between positive and negative entitlements, are not always clearly made, nor are they always helpful. One must not depart from the context of the purposive approach articulated by this Court in R. v. Big M Drug Mart Ltd., 1985 CanLII 69 (SCC), [1985] 1 S.C.R. 
295. Under this approach, a situation might arise in which, in order to make a fundamental freedom meaningful, a posture of restraint would not be enough, and positive governmental action might be required. This might, for example, take the form of legislative intervention aimed at preventing certain conditions which muzzle expression, or ensuring public access to certain kinds of information. [Cited more recently in Ontario (Attorney General) v. Fraser, [2011] 2 S.C.R. 3 at para. 69]

[66] Access to documents in government hands may be constitutionally protected where it is shown to be a necessary precondition of meaningful expression, provided that, as here, it does not encroach on protected privileges and is compatible with the oversight of therapeutic products by the Minister (see Ontario (Public Safety and Security) v. Criminal Lawyers' Association, [2010] 1 S.C.R. 815 at para. 5). For our purposes, it is sufficient that eligible persons cannot research without the data and that they cannot publish in a number of journals without disclosing the data. As set out below, there are also the rights of individuals using, or considering using, therapeutic products to consider.

[67] The Supreme Court in Ontario (Public Safety and Security) v. Criminal Lawyers' Association, [2010] 1 S.C.R. 815 at para. 37 cited from Louis D. Brandeis' famous 1913 article in Harper's Weekly entitled "What Publicity Can Do": "Sunlight is said to be the best of disinfectants ...." This lead the Court to comment that, "[o]pen government requires that the citizenry be granted access to government records when it is necessary to meaningful public debate on the conduct of government institutions." So too, access to drug data is necessary to meaningful public debate relating to the safety and effectiveness of therapeutic products such as Vioxx and Paxil. In both those cases, the disclosure of information known to the drug manufacturer and, at least in the case of Vioxx, to the regulator, may have brought safety concerns about their use to light and saved the lives of Canadians.

[68] While requesters and the public at large may have a constitutional right of access to drug data, our primary concern is removing a barrier to expression. In this case, would-be requesters may be eligible for disclosure, but would be nonetheless excluded 
in the event they refused to maintain the data confidential and omit drug data from their research publications. As in Greater Vancouver Transportation Authority, supra these requesters would be rejected, not on the basis that access to drug data is unavailable to them, but rather because of their refusal to enter into a confidentiality agreement that limits the content of their research publications. Would-be requesters should, in our view, be entitled to receive information and to express themselves without undue state interference with the content of their expression.

[69] In addition to s. 2(b) of the Charter, the issue of access to safety and effectiveness data may also engage the right to life and security of the person protected by s. 7 . It is not necessary, in our view, to address the issue of positive versus negative rights here because the Supreme Court recognized in Gosselin v. Quebec (Attorney General), [2002] 4 S.C.R. 429 at para. 83, that a positive obligation to sustain life, liberty, or security of the person may be made out in special circumstances. In this respect, we emphasize that the failure to make available information about Vioxx and Paxil, to name but two examples, are causally related to the deaths of a number of individuals.

[70] Similar reasoning underpinning Chaoulli v. Quebec (AG), [2005] 1 S.C.R. 791, where a majority of the Supreme Court ruled that s. 1 of the Quebec Charter of Human Rights and Freedoms, which closely resembles s. 7 of the Canadian Charter, had been violated by a legislative prohibition on private insurance, because it prevented individuals from taking out their own insurance in order to obtain timely access to health care. Preventing access to and public discussion of relevant health information held by the government also appears to seriously hinder people's ability to make decisions in relation to their health and physical integrity.

[71] The right to life and security of the person is at stake because access to clinical data held by Health Canada is crucial to be properly informed for decisions that relate to people's health and physical integrity. As some of the controversies mentioned before indicate, independent analysis of data has in several instances resulted in the discovery of significant safety and efficacy problems related to pharmaceutical products. Courts in other jurisdictions have recognized the importance of access to information held by governmental agencies to enable people to make decisions in relation to their health and 
safety. For example, the European Court of Human Rights ruled in Öneryildiz v. Turkey (2004-XII Eur. Ct. H.R., November 30, 2004) that the Turkish government had violated the right to life of people living close to a garbage pit where a methane explosion killed nine people. The Court criticized the government for not having put in place proper procedures to prevent the exposure, but it also stated that "the public's right to information . . . may also, in principle, be relied on for the protection of the right to life."

[72] The European Court of Human Rights case law with respect to the right to the protection of private and family life can also be used as a relevant source to explore the content of the Canadian Charter's right to life, liberty and security of the person in the context of health protection. The Charter does not have an equivalent 'right to privacy', but the broad interpretation of the right to the protection of private and family life in the case law of the European Court of Human Rights brings this right close to the Charter's s. 7 right. For example, in Roche $v$. the United Kingdom, the ECHR recognized that the right to the protection of private life of a former soldier had been violated because the government's failure to provide easy access to all relevant data about the risks of experiments to which he had been submitted caused considerable anxiety. The Court ruled that "the State has not fulfilled the positive obligations to provide an effective and accessible procedure enabling the applicant to have access to all relevant and appropriate information that would allow him to assess any risk to which he had been exposed." (Roche v. United Kingdom, 43 Eur. Ct. H.R. 30 (2006) at para. 168). Other caselaw of the European Court of Human Rights confirms the obligation of governments to share information it has at its disposal that allows citizens to be properly informed of factors that create a risk to their health and well-being (see Lemmens, Trudo, "Pharmaceutical Knowledge Governance: A Human Rights Perspective" (2013) 41(1) Journal of Law, Medicine and Ethics at 165-169).

[73] We would like to point out also the link that can exist between the protection of freedom of expression and the right to life and security of the person. The restrictions imposed by the Draft Guidance also make it impossible for others, including media outlets, to fulfill their important role in participating in democratic debate about issues of public important, in this case the health and wellbeing of Canadians. In the context of safety of pharmaceutical products and freedom of expression arguments, the European 
Court of Human Rights case in The Sunday Times v. The United Kingdom (30 Eur. Ct. H.R. (ser. A) at 245 (1979)) is worth mentioning here. The case dealt with the aftermath of the Thalidomide disaster. The European Court of Human Rights ruled that an injunction imposed on the Sunday Times preventing it from discussing the details of the settlement clauses between the government and parents of affected children was a violation of freedom of expression. The Court emphasized that when it comes to matters of public health, the public has the right to be properly informed. In the international context, several other courts, tribunals, and human rights committees have also recognized the importance of access to information and information-sharing in the context of the debate over health-related rights (see in general Lemmens, Trudo \& Candice Telfer, "Access to Information and the Right to Health: The Human Rights Case for Clinical Trials Transparency" (2012) 31(1) Am. J. Law \& Med. 63 at 38-41).

\section{Conclusion}

[74] We have argued here that Health Canada's Draft Guidance imposes duties and liabilities on the recipients of clinical data, which have no basis in the legislation that explicitly enables Health Canada to disclose information. To the extent that the restrictions impose a duty to sign a confidentiality agreement and prevent those receiving the information from Health Canada to disclose the data to third parties, they exceed the power granted by Parliament. Furthermore, we argued that several limitations imposed on the disclosure of data are at odds with the purpose of the amendments and the rest of the statutory scheme. Some significantly delay access to data, others create significant difficulties that hinder a proper research use of het data, and still others make a useful sharing and publication of the data hard if not impossible, thus frustrating the purpose of Vanessa's Law of improving the safety of pharmaceuticals and the protection of the public.

[75] We further argued that the restrictions embedded in the Draft Guidance may also infringe the Charter of Rights and Freedoms, more specifically s. 2(b) and s. 7. To the extent that these restrictions hinder a proper research use and public sharing of research results, they infringe researchers' freedom of expression. The Draft Guidance makes proper sharing of data in the context of research, and the subsequent public debate of 
these research findings unjustifiable difficult. We also put forward that the barriers to proper sharing of data make it excessively difficult for individuals to obtain important health related data to inform their own health care related decision. To the extent that they hinder individuals from obtaining relevant information about the risks to their health and physical wellbeing, they also infringe the right to life and security of the person. We pointed out that this connection to the right to be properly informed of relevant health risks and the right to life and security of the person has already been recognized in other jurisdictions and in the context of related fundamental rights provisions.

[76] We also reiterated in this memorandum our objection to Health Canada's characterisation of clinical data as CBI. Indeed, most of the problems of the Draft Guidance stem from this overly broad characterisation of $\mathrm{CBI}$. We put forward that clinical data should in principle not be considered CBI. We urge Health Canada to follow the lead of the European Medicines Agency and to explicitly recognize that clinical data are in principle not $\mathrm{CBI}$, and that those insisting on data secrecy have to provide evidence of the $\mathrm{CBI}$ nature of the data, and of the need for continued confidentiality of the data.

[77] It is worth noting that in the context of the development of its 2014 data sharing policy, the EMA originally also created significant barriers to the proper research use of clinical data even though it did not characterize the data as CBI. Faced with criticism on how its original draft policy was making it excessively cumbersome for researchers and health care advocates to conduct proper public health oriented research, the EMA significantly changed its policy and restored its stated commitment to data transparency. Health Canada has received the power from Parliament to promote public health and safety through data sharing. We urge Health Canada to use this power wisely and responsibly. To that end, we call upon Health Canada to remove the four limitations we identify above from the Draft Guidance regarding s. 21.1(3)(c) of the F\&D Act. 